\title{
A caminho da Cidade das Onças: diálogos sobre sonhos no percurso para a Serra Grande- Metrópole dos Hupd'äh
}

DoI

http://dx.doi.org/10.11606/ 2179-0892.ra.2018.145528

\author{
Danilo Paiva Ramos \\ - Universidade Federal da Bahia / Salvador, BA, Brasil \\ $\checkmark$ danilo.paiva@ufba.br
}

\section{RESUMO}

Nesse trabalho, procuro entender como meus interlocutores Hupd'äh relacionam conversas sobre sonhos e eventos ocorridos durante uma viagem que fizemos à /Paç Pög/, "Serra Grande". A questão da relação entre sonhos e deslocamentos cósmicos vem sendo amplamente discutida tanto em estudos sobre os povos ameríndios, como para povos da melanésia. Chama a atenção o modo como tais itinerários oníricos levam a vivências em diversos planos cósmicos e também em cidades grandes, onde encontros, diálogos e interações com militares, missionários, comerciantes. Tomando como referência a teoria dialógica da enunciação de Bakhtin (1981) e a abordagem centrada no discurso de Urban (2000), procuro mostrar como, nas interações verbais entre os viajantes sobre sonhos, processos intersubjetivos de instituição de sentidos vão emaranhando as situações do percurso àquelas vividas oniricamente através de um modo específico de indexicalização. Em que medida a justaposição ontológica da Cidade das Onças que emerge desses diálogos sobre sonhos vai delineando uma percepção crítica quanto aos acelerados processos de mudança, expropriação e violência suscitados pelos cada vez mais constantes deslocamentos para a cidade de São Gabriel da Cachoeira (AM)? 


\author{
Àcaça \\ Lambedor de feridas! \\ Porque a fera que dorme em você \\ Deita no seu pensamento \\ E você pode ser a comida.
}

(Sérgio Vaz)

\section{INTRODUÇÃo}

Ainda sentindo o cheiro da fumaça da tocha que nos protegera das onças durante toda a noite, começamos a despertar. Estávamos sem rumo desde a tarde anterior quando perdemos o rastro da trilha para a "Serra Grande", /Paç Pög/. Desesperançosos, alguns já diziam que o melhor seria desistir de nossa escalada. Logo cedo, ainda em suas redes, alguns viajantes começaram a conversar comigo sobre seus sonhos noturnos. Nos itinerários oníricos, visitaram o topo da serra, comeram coca com antepassados mortos e beberam caxiri na aldeia de / Tat Dëh/. Terminada a conversa, meus interlocutores levantaram-se e, confiantes, começaram os preparativos para nossa nova partida.

De modo surpreendente, durante a caminhada, as conversas sobre sonhos foram revelando a Serra Grande como uma Cidade Grande, o perigoso domínio de onças e soldados. A espontaneidade e a intimidade que marcavam as conversas sobre sonhos tornavam difícil o registro audiovisual. As anotações em caderno de campo, momentos após as conversas, foram a forma que encontrei para registrar não só os enunciados, mas também os gestos, posturas e demais aspectos relevantes à situação comunicativa.

Por um lado, a caminhada fazia parte do conjunto de ações de desenvolvimento do Plano de Gestão Territorial e Ambiental (PGTA)' , através do qual as lideranças Hupd'äh vêm buscando a proteção territorial e segurança nas incursões à cidade de São Gabriel. Por outro lado, a viagem à Serra Grande é uma peregrinação marcada por ações ritualizadas ${ }^{2}$ que, mobilizando a atenção dos caminhantes para suas próprias ações, permite aos jovens e anciãos posicionarem-se em campos relacionais para a interação perigosa com antepassados, Centes-Onça, Gentes-Sombra e Brancos agindo entre pontos de vista (Humphrey e Laidlaw, 2004).

Entendendo com Bakhtin que "só a corrente da comunicação verbal fornece à palavra a luz de sua significação" (1981: 132), procura-se analisar como, nas conversas sobre sonhos, a compreensão surge sob a forma de diálogo, na interação entre interlocutores para situar processos de instituição de sentido. Urban (2000) afirma que as interações verbais que constituem diálogos oscilam entre a ênfase semântica (definição por conteúdo), com destaque para as conversas

1 Ver: 2013. Plano de Gestão Territorial e Ambiental de Terras Indígenas: Orientações para Elaboração. Brasília, Funai.

2 A abordagem de Humphrey e Laidlaw (2004) permite tomar o ritual como uma qualidade da ação, e não como uma classe de eventos ou instituições. 
cotidianas, e a ênfase pragmática (definição pela forma), com destaque para os diálogos cerimoniais. Tomando as conversas sobre sonhos dos viajantes hup como pertencentes a esse primeiro modo, faz-se importante entender como, pela sucessão de turnos, os interlocutores respondem, amplificam ou estendem o conteúdo discursivo. Os diálogos revelaram-se plenos de expressões linguísticas conectadas ou direcionadas aos contextos de referência para os interlocutores, permitindo, assim, uma análise da indexicalidade dos signos-veículos situados pelo aqui e agora da situação enunciativa (Silverstein, 1992). Como definido por Silverstein, "indexical sign-vehicles point from an origin that is established in, by and "at" their occurring as the here-and-now "center" or tail, as it were, of a semiotic arrow" (Silverstein, 1992: 55). Para enfocar esses diálogos na concretude das situações diárias, tomo como referência o conceito de mundo vivido, tal como delineado por Cow (2001), e busco analisar as conversas como modos de ação que revelam dimensões cruciais da socialidade hup como um sistema em estado de transformação a combinar imagens míticas, oníricas e históricas em permanente mutação (Cow, 2001: 26-27).

A expressão verbal da percepção de deslocamentos reais durante o sono impõe a necessidade de assumir uma visão alternativa da fala, não como a expressão de pensamentos internos, mas como um dos modos da pessoa manifestar sua presença no mundo pelo posicionamento em percursos relacionais (Ingold, 2000: 103). Assim, a perspectiva de Ingold sobre como a percepção do entorno se dá pelo engajamento mútuo de caminhantes em percursos de observação e ação ajuda a estar atento à instrução dos mais jovens por processos de educação da atenção (2000: 22). Entretanto, a atenção dos caminhantes volta-se para as potências exteriores de Onças e Brancos, revelando intenções de predação e a predominância de dados pontos de vista imanentes não a um ambiente, como para a ecologia da vida (Ingold, 2000), mas a uma multiplicidade de mundos, planos-cósmicos a enredar-se de modo tenso.

A abordagem de Viveiros de Castro (2002) sobre a predação ontológica como um mecanismo que constitui as socialidades ameríndias por aquilo que está fora delas, operando a partir da "vingança canibal e voracidade ideológica", torna-se instigante para analisar essas interações como diálogos transespecíficos e a percepção dos caminhantes de perspectivas Outras (Viveiros de Castro, 2002, 2007; Andrello, 2006). Pensando com Viveiros de Castro, os dados sobre a percepção dos viajantes de sons e interações oníricas, sinais diacríticos das fronteiras entre a Terra dos Hupd'äh e a Cidade das Onças, podem ser vistos como limites - não enquanto limitações geométricas que constrangem e definem formas substanciais - mas como limites-tensão, "passagens ao limite" de um mundo possível a outro, onde se evidenciam as capacidades xamânicas virtuais dos caminhantes (2002: 119-121). 
Severi (2002) ajuda a perceber como esse percurso iniciático para a Serra Grande entrelaça uma memória narrativa-estabelecida por séries de histórias - a uma memória ritual-marcada pelo esquecimento de certas imagens e pela complexificação de imagens contraditórias de "brancos" e "onças", "cidades" e "terras-mundos" (Severi, 2002: 148). Assim, através do estudo dos diálogos oníricos busco refletir sobre sequências de imagens quiméricas cujo entendimento semântico deve combinar-se ao entendimento das condições pragmáticas da ação ritual (Severi, 2004: 817). De modo complementar, a partir do contraste entre ações ritualizadas e ações não ritualizadas, Humphrey e Laidlaw enfatizam a importância da atenção do agente para sua própria ação (2004: 2-5). Assim, situações surgidas no curso das viagens podem ser tomadas como transformações sutis de ações correntes promovidas pelos caminhantes. Essas transformações revelam histórias e características específicas da ação performada que alteram sentidos, formas de interação e de intenção dos agentes (Humphreye Laidlaw, 2004: 90).

Amparado por esse arranjo teórico-metodológico, procuro mostrar a centralidade dos diálogos sobre sonhos para a circulação de saberes e reflexão crítica sobre um mundo vivido que, através de caminhos diversos, atravessa e entrelaça paragens florestais, urbanas e mito-históricas.

\section{MOBILIDADE ONÍRICA E DISCURSO}

Os Hupd'äh habitam a região do Alto Rio Negro (AM) na fronteira entre o Brasil e a Colômbia. Suas comunidades situam-se na área interfluvial dos rios Tiquié e Papuri. A população é estimada num total de 1.500 indivíduos distribuídos em aproximadamente 35 aldeias (Athias, 2006; Epps, 2008). A língua Hup pertence à família linguística Nadahup (Maku) (Epps, 2008). A estrutura social hup tem nos clãs agnáticos seus segmentos básicos de constituição e de diferenciação. $O$ contato teve início com as frentes de colonização desde o século XVIII, mas foi apenas nas décadas de 1960 e 1970 do século XX que os missionários salesianos começaram ações voltadas à evangelização e à escolarização. Nos últimos anos, centenas de pessoas hupd'äh têm rumado à cidade de São Gabriel para a expedição de documentos, retirada de benefícios sociais e realização de compras de mercadorias. Uma vez no meio urbano, ocupam áreas à beira do Rio Negro onde têm dificuldade de alimentação e estão sujeitos a diversas violências como roubos, racismo, estupros e assassinatos.

Em 1978, Reid mostrava como, práticas relativas aos sonhos, os Hupd'äh transformam símbolos experienciados oniricamente em significados para a vida quando se está acordado. Segundo o pesquisador, sempre que descrevem um sonho, os Hupd'äh referem-se a um símbolo ou a uma ação, não havendo a des- 
crição de um sonho como uma história ou uma sequência narrativa de eventos. Haveria uma postura marcadamente aberta e pronta a dar uma interpretação do sonho, por vezes seguida de uma sequência de outros sonhos e interpretações conectadas ao primeiro. Entendidos como deslocamentos do espírito pelo cosmos, os sonhos permitiriam a interação com antepassados e com seres diversos, ampliando o conhecimento sobre o universo. Assumindo uma perspectiva estruturalista, busca apresentar os modos de padronização em "chaves concisas" (lista de códigos - code book) de significados para a composição de num sistema interpretativo de códigos (Reid, 1978). Em nossa viagem de 2016, se era ao longo de percursos de observação que jovens e anciãos hupd'äh percebiam o/sugut nii/, "estar na floresta" o "entorno florestal", em que medida as conversas sobre sonhos tematizavam os itinerários percorridos durante o sono?

Como mostra Lohmann (2003), as experiências oníricas de movimento que levam a viagens através do tempo, do espaço e de dimensões espirituais vêm sendo amplamente documentadas pelos estudos etnográficos sobre povos das mais diferentes partes do mundo e levaram, recentemente, pesquisadores da Melanésia, Austrália e Indonésia (Pacífico Oeste) a proporem uma Antropologia das Viagens Oníricas. Já Tylor [1871], Firth (1934), Lincoln (1935) e Williams (1936) descreveram percepções de sonhos como movimentos do espírito itinerante a suscitar visões de mortos ou de pessoas distantes para povos da Polinésia, Papua Nova Guiné e América do Norte. Malinowski [1927] descreveu a importância do caráter premonitório dos sonhos dos viajantes das expedições do kula que suscitavam a realização de encantamentos para incutir bons sonhos nos parceiros de troca.

Nos estudos sobre povos ameríndios, a questão da mobilidade, percepção e comunicação das experiências oníricas são desenvolvidas através de pesquisas que enfatizam as dimensões semióticas, psicoanalíticas e performáticas dos enunciados sobre sonhos. Segundo Teddlock (1987), os estudos iniciados nos anos 1940, como os de Sears (1948), Eggan (1952) e O'Neil (1965) visavam à constituição de corpus de relatos de sonhos abordados a partir de seus conteúdos possibilitando uma perspectiva comparativa. Para a região do Uaupés, Reichel-Dolmatoff (1986) descreve a dimensão clarividente e simbólica dos sonhos dos Desana que relacionam visões e modos de relação com o mundo sobrenatural. A capacidade xamânica do vôo mágico permite ao pajé sair da biosfera e penetrar em outro plano de existência. Ainda sobre os Desana, Buchillet (1983) afirma que os sonhos podem sinalizar doenças futuras e a ação maléfica de um xamã. Durante o sono, o espírito separa-se temporariamente do corpo e peregrina pelo mundo, estando sujeito a encontros com seres diversos e ao perigo de ser capturado. O foco nas narrativas sobre sonhos dos Siona, permite a Langdon (2004) desenvolver uma reflexão interessante sobre a subjetividade e as representações de si nos sonhos dos Siona. Explorando a relação entre experiência 
extraordinária, performance e perspectiva, a autora (Langdon, 2013) analisa as narrativas dos Siona sobre a viagem à casa das onças, fundamental para o aprendizado xamânico .

Comentando sobre a importância dos sonhos em que os xamãs hupd'äh visitam as cidades dos brancos, Marques (2015) salienta que tais deslocamentos permitem a descrição de modos de vida de Outrem, humanos e não humanos, onde a "cidade", do ponto de vista hup, é a imagem geral da multiplicidade (p. 237). Seguindo essa pista lançada pelo pesquisador, entendo que as conversas sobre sonhos entre jovens e anciãos no curso da viagem são interações verbais cotidianas que situam processos dialógicos de constituição de sentido para a ação, modos de circulação de saberes e habilidades xamânicas fundamentais para o posicionamento tático numa urbanidade predatória, expansiva e difusa.

\section{DIÁRIO DE VIAGEM E DIÁLOCOS SOBRE SONHOS}

Nossa incursão à Serra Grande surgia da necessidade de "cercar", /ta'/, proteger a terra hup das ameaças dos empreendimentos de mineração e abertura de estradas na floresta que começaram a surgir com toda a força nos últimos anos resultando de interesses estatais e militares-estratégicos. Em/Tat Dëh/, realizamos reuniões comunitárias na palhoça para a discussão sobre os problemas atuais e planejamento do início do diagnóstico participativo que envolveria a continuidade da ação de etnomapeamento da terra Hup. Assessores dos Hupd'äh para o PCTA, a linguista Patience Epps e eu estávamos também desenvolvendo atividades de pesquisa focadas no discurso xamânico e contato linguístico. Fazendo uso de câmeras, GPS, gravadores e cadernos de campo, auxiliaríamos nossos companheiros no registro e documentação dessas paragens ao longo dos seis dias de caminhada.

Na roda de coca ${ }^{4}$ da noite anterior à nossa partida, João Paulo, filho do pajé Armando, voluntariou-se a liderar o grupo. Grande conhecedor dos caminhos que levam à Serra Grande, nosso guia combinava duas habilidades, a destreza para a caça que o fazia rumar de tempos em tempos para tirar curare na Serra Pequena, e o processo de aprendizado xamânico iniciado com seu pai por meio da ingestão ritual do caarpi e das idas à Serra Grande. Outro voluntário era o senhor João Brasil, o /Kowhõ/ (paca)5, que ficaria responsável por realizar ações xamânicas de cura e proteção durante a viagem. Entre uma cuia de coca e outra, meus interlocutores foram assumindo papéis e, a partir daí, convidaram jovens como José Maria e Edmar e homens maduros como Valdemar, Norberto, pai de Edmar, e José para juntarem-se a nós. Gravitando em torno de /Kowhõ/, o grupo apresentava uma composição interessante, consolidando-se na liderança de um "dono da terra", João Paulo, do clã /Sökw'ät Noh K'öd Tẽh/, que seria acompanhado por membros de clãs afins (/Dög M'eh Tẽh/e / /h Noh Teh/) e por não indígenas
3 Num trabalho recente Kelly (2016) enfoca a relação entre os diálogos cerimonias Yanomami e o modo como os sonhos são tomados como fontes de saberes oriundos de lugares distantes (Kelly, 2016: 7)

4 Para um estudo aprofundado ver: Ramos (2013)

$5 \quad$ Apelido a partir de palavra da língua Tukano utilizada num divertido câmbio de código. 
pesquisadores. Quanto aos grupos etários, a presença de dois jovens, um senhor e homens maduros delineava nossa incursão como um percurso iniciático.

A viagem à Serra Grande é vista como uma incursão que possibilita aos caminhantes a realização de um grande feito. A subida ao topo é narrada por muitos como uma experiência fundamental para a preparação para a atividade xamânica. Ainda hoje benzedores e pajés dirigem-se à serra para visitar os poços, banhar-se e beber a água que fortalece o corpo e faz sonhar. Nos sonhos, encontram antepassados, conversam com eles e escutam encantamentos. A serra é também o local de destino do /hãwäg/, "pessoa-sopro", do morto depois do enterro e da realização de sua caminhada póstuma pela floresta. Nas imediações desse grande marco no relevo regional, outra montanha, menor, denominada /Paç Tẽh/, Serra Pequena, é o lugar onde os caçadores colhem o curare venenoso para aniquilar suas presas.

É possível pensar a noção de pessoa hupd'äh a partir da composição do Ser pelo corpo, /sap/, pelo sopro vital, /hãwäg/ e pela sombra, /b'atịb'/. Quando a pessoa envelhece, o /hãwäg/ atinge o tamanho do corpo e, com a morte, viaja como pessoa-sopro (duplo) para a Serra Grande. Após a morte, o /b'atịb' deixa o corpo como um duplo-sombra e junta-se a outros seres sombra que habitam a floresta. Em Hup, a palavra para "pensamento", /wä’këy/, evoca os sentidos dos verbos "ouvir", /wä'/, e "ver", /këy/. Pensamento e sopro vital são materialmente feitos de /hãg-sak/, "ar/respiração/pulsação", /pud dëh/, "leite”, e /yõh dëh/, "água pura". Quando o xamã ou o sonhador movimenta-se pelo cosmos, a porção líquida desses princípios vitais permanece no corpo e apenas a porção ar, sopro, viaja pelo cosmos. Portanto, a viagem xamânica e os deslocamentos oníricos tornam-se possíveis através da reconfiguração de si como pessoa-sopro (pensamento-sopro vital) pela continuidade que atravessa o sopro, a fala, o leite e a água-pura, substâncias vitais mobilizadas pelas ações de deitar-se na rede, sentar-se no banco para benzer e de andar pelos caminhos (Ramos, 2013).

O xamanismo Hup é protagonizado pelos pajés, /säw/, e pelos benzedores, / bi'id däh/. Bebendo caarpi, inalando paricá e obedecendo a diversas restrições alimentares e sexuais, os pajés vão adquirindo habilidades pelos sonhos, pela iniciação guiada por um pajé mentor, e pelas conversas com anciões nas rodas de consumo de coca noturnas onde discutem encantamentos, narram mitos e comentam sobre os percursos percorridos durante o dia. Os pajés e benzedores são capazes, em graus diferenciados de competência, de curar, proteger e agredir através de "sopros", /bi'id/, também chamados regionalmente de benzimentos. Objetos intermediários como cigarros, cuias com bebida, pedaços de beijú podem ser xamanizados e utilizados como veículos para os quais um benzedor murmura e sopra suas ações de deslocamento como pessoa-sopro pelo cosmos para acalmar ou instigar a fúria de diversos seres, de acordo com sua intenção. 
As palavras-ação xamânicas - penetram o objeto que as abduz para depois serem transduzidas para o corpo do doente ou vítima através da fumaça ou matéria consumida do alimento ou bebida (Buchillet, 1983; Athias, 1998; Ramos, 2013; Lolli, 2010).

Tiwit, 13 de julho de 2016.

Naquele dia, caminhamos até a beira do /Dëh Mi Bab/. Kow e os rapazes foram identificando os tipos de solo pelos quais passávamos. Valdemar indicava as árvores que cresciam em cada solo. Apontando para uma /Mot Tëg/, "árvore da fruta mot", Valdemar disse que os antigos costumavam tirar seu látex e aplicá-lo sobre o rosto para limparem-se e purificarem-se. Quando todos tinham saído para pescar no igarapé, Valdemar ficou para preparar a lenha do fogo. Acocorado ao seu lado, comecei a ajudá-lo. Juntos, lembrávamos de nossa incursão anterior à Serra Grande em 2012. Ele então contou que tivera um sonho na noite anterior à nossa viagem.

\section{Língua Hup}

Danilo (D). Tuhup n'ikan, paç busö’an.

Valdemar (V). Tuhup hisap!!!

V. Surara sõh niih ãh Niro.

D. Hip m'e? Surara däh?

V. S'äbäy s'am. Surara. Bola muhuy, São Gabriel an.

V. Ya'am däh hid nih häwãg.

\section{Tradução}

Danilo (D). Muito bonito para lá, para lá no topo da Serra Grande.

Valdemar (V). Muito bonito!

V. Tenho sonho com soldados, Danilo.

D. Quando? Soldados?

V. Ontem. Soldados. Jogando bola lá em São Gabriel.

V. É o fantasma/sôpro vital das onças.

A lembrança da incursão anterior à Serra Grande apresenta um tema para a sequência de turnos. $O$ processo de indexicalização estabelece-se na referência dêitica à Serra Grande, ao sonho na aldeia e ao estranho jogo de futebol /São 
Cabriel an/, "Para lá em São Gabriel". Constitui-se uma dimensão espacial que justapõe esses três loci de sociabilidade marcantes para a situação histórica atual. /Surara sõh niih ãh/, "tenho sonho com soldados", revela o caráter pessoal da experiência onírica constituída pelo "eu", /ãh/, discursivo e por uma alteridade da terceira pessoa "soldado" ampliada na sentença seguinte pela marca do plural /- d'äh/. /Bola muhuy/, "estar jogando bola", com esses outros "brancos" potencialmente assassinos aponta o posicionamento de si numa /muhuy/, "brincadeira", que configura um tenso campo relacional. O ponto de vista desses soldados jogadores revela-se o das onças predadoras, habitantes da serra, já que sob a aparência militar elas incluíam o viajante na brincadeira de "branco" na cidade.

Os pontos de vista do sonhador hup, dos soldados e das onças intercambiam-se polifonicamente no discurso e a sentença final, metaforicamente, parece expressar um enquadramento que institui o sentido aos turnos precedentes, pois se os soldados são onças, o jogo de futebol pode ser caça ou guerra e a Serra Grande bela é uma perigosa São Gabriel (Bauman, 1977). O sonho fora tomado por Valdemar como um /sõh ni pay/, um "sonhar ruim", que mostrava a necessidade de sermos logo benzidos com o "encantamento dos caminhos". Assim, pela interlocução uma cadeia fractal de pontos de vista Outros vão tramando o tecido do discurso polifônico nas tensões entre temas e significações, eventos reportados e vindouros (Lima, 2005).

Tiwit, 14 de julho de 2016.

As redes molhadas de alguns davam notícias dos transtornos que a chuva da madrugada causara. Despertei logo que o sol nasceu e comecei a arrumar as minhas coisas para a partida. Estávamos no segundo dia de viagem e tínhamos agora um percurso difícil de caminhos fechados pela mata. Ao meu lado, o jovem J. Maria abriu sua rede para a luz entrar e saudou-me.

\section{Língua Hup}

José Maria (JM): Säwä'äy am, Niro!

Danilo (D): Säwä'äy!

Naw aman sõh ni?

\section{Tradução}

José Maria (JM): Você está acordando, Danilo!

Danilo (D): Acordando!

Tem sonho bom para você? 


\section{Língua Hup}

JM: Sõh ni pay, Niro! Hupdan ãh Meh yit'th. Pay.

D: Pay hisap...

JM. Ãh säw niih. Hõp wed nih, charque wed nih.

B'a', won, ken, b'tyi'.

\section{Tradução}

JM: Tenho sonho ruim, Danilo! Matando um homem. Horrível.

D. Muito ruim.

JM. Eu sou xamã. Não como peixe, não como charque. Apenas beijú, mingau e farinha.

Em nosso diálogo, ]. Maria revela ter tido um sonho ruim em que matava um homem. Virando-se para Kow, ao seu lado, ele brincou que era um xamã e que não comia peixes nem carne de charque, apenas beijú, mingau e farinha. Alude assim à dieta que possibilita ao neófito limpar o corpo da energia quente (/K't') presente nas carnes e concentrar em si grande quantidade da energia fria (/Tut/) de alimentos à base de mandioca. Como na couvade, esse regime alimentar resfria, endurece e fortalece o corpo, agindo como a água dos poços no alto da Serra Grande. Apesar do "sonhar ruim" sinalizar a necessidade de um benzimento protetivo a ser soprado por Kow, a piada de ]. Maria, da qual rimos largamente, situa-o como um pajé capaz de agredir oniricamente.

Na sequência, Kow levantou-se para mostrar como vestiam-se os antigos. "Apenas cobriam o pênis", disse José Maria. "Os missionários ofereciam terçado, sabão, sal e assim, viraram /yo'om ĩh/, 'patrões'. Não trocavam, davam as mercadorias como presentes. Assim, convenceram os moradores da antiga aldeia de /Wõy Moyo/ a mudarem-se para perto do rio Tiquié", disse Kow. Em português, ]. Maria referiu-se ao "tempo do dinheiro" quando passaram a conseguir mercadorias. Segundo ele, "antes estavam esquecidos". Kow preparou, então, um cigarro benzido para proteger-nos das ameaças sinalizadas pelo/sõh nii pay/, "sonhar ruim".

Nossa caminhada daquele dia fora difícil. Os terçados perdiam o fio rapidamente e os /patd'äh/, "cortadores", que iam à frente logo se cansavam de lutar contra a densa cortina vegetal. Os rapazes apontavam árvores como a /Mot tëg/, a /Pãhãy tëg/, "sorva”, e a /Yãh tëg/, todas frutíferas. Estávamos próximos a / Pëd Dëh Moy Höd/, morada antiga que Kow conheceu quando criança antes da chegada dos missionários. Em seus comentários, o mentor inseria a percepção do entorno dos rapazes numa memória social dos cultivos arborícolas dos antepassados que garantiam a fartura necessária para as trocas dos Dabucuri e para o preparo dos caxiris (Severi, 2002). A relação com os brancos era tematizada pela 
evitação do charque e, em seguida, pela história do contato com os missionários e da aquisição de mercadorias. Durante a caminhada, a indicação de árvores cultivadas pelos antigos ia inserindo os viajantes numa região de memórias de uma vida antes dos missionários e do charque que atrapalha o aprendizado xamânico. Assim, o ato de indicar é também um ato de memória ritual onde as árvores destacadas são, iconicamente, imagens quiméricas a concentrar lembranças de antepassados e modos de habitar a /Hupd'äh nih s'ah/, a "terra dos Hupd'äh" (Severi, 2002). O sonho é classificado negativamente como /sõh ni pay/, "sonhar ruim". O verbo /meh/, "matar", aponta a ação realizada pelo sujeito do discurso contra um homem hup. No evento onírico, meu interlocutor, um rapaz, age como um xamã para matar outra pessoa. Define-se reflexiva e ironicamente como um xamã. O emprego do / $\mathrm{n}+\mathrm{h} /$ - marca do negativo-evidencia o papel do jovem pajé pelas restrições alimentares que abarcam o "charque", uma comida de "branco".

Enquanto o "futebol na cidade com soldados-onça" salienta a intenção predatória contra Valdemar [13.07], o câmbio de código (code swiching) ${ }^{6}$ com o emprego da palavra "charque" em português abre a conversa que contrasta os costumes dos antigos hupd'äh às ações dos missionários-patrões e ao "tempo do dinheiro" das mercadorias. Entendo que assumir oniricamente a posição do xamã sem iniciação num tempo do dinheiro e do charque é algo engraçado e perigoso. Em nosso caminho, os apontamentos de árvores cultivadas pelos antigos ia constituindo uma dêixis comunicativa importante para que os mais jovens percebessem os índices de um "tempo do dabucuri" quando as frutas cultivadas eram fartas e havia muita festa, contrapondo-se ao "tempo do dinheiro e ao tempo dos missionários". No despertar, as imagens oníricas e históricas das conversas ao longo do caminho são reveladoras quanto a transformações no mundo vivido dos Hupd'äh e quanto a uma memória ritual que condensa imagens complexas e plenas de contradições e tensões (Gow, 2011; Severi, 2002).

Tiwit, 15 de julho 2016.

Durante a madrugada, em uma de suas incursões à pesca, Valdemar caçou uma tartaruga vermelha. Fui ver o bicho que agonizava perto da fogueira. Acocorado, ele jogava um pouco mais de lenha para aumentar o fogo e cozinhar a iguaria. Fiquei mexendo um pouco os peixes espetados a assar. Ele, então, contou-me de seu sonho e perguntou sobre o meu. 


\section{Língua Hup}

Valdemar (V): ãyd'äh ãh sõh ni.

Danilo (D): ãyd'äh?

V. Ya'am ãyd'äh.

Paç an d'uuy däh.

Am ta?

D. Mariana

ãh sõh ni.

V. Mariana, owwww!

\section{Tradução}

V. Eu tenho sonho com mulheres.

D. Mulheres?

V. Mulheres onça.

Aquelas da Serra Grande.

Evocê?

D. Tenho sonho

com a Mariana.

V. Mariana, hahahahaha!

Durante a madrugada, é comum que os viajantes deixem o acampamento para pescar ou explorar as cabeceiras dos igarapés em busca de jacarés e tartarugas. O sono alterna-se com a pesca e caça e era em meio a essa alternância que meus companheiros experienciavam os deslocamentos oníricos. O sonho de Valdemar revela a perigosa relação com as mulheres-onça da serra. Com aparência humana hup, belas e sedutoras, podem fazer com que a pessoa esqueça dos seus, assuma a perspectiva felina e aceite ir coabitar as paragens rochosas da Cidade das Onças. Ao contar, ele voltou seu olhar para a Serra Grande, indicando o lugar onde tinha se dado o encontro. Meu sonho, com minha esposa, não é tomado como um sonho de nostalgia ou saudade. Os sonhos com a esposa sinalizam abstinência de intercurso sexual e ejaculação involuntária, o que pode agredir o olfato apurado das Gentes-Onça e Gentes-Sombra. Enquanto guardávamos nossas redes, Kow acendeu um cigarro benzido com o "encantamento dos caminhos" para que seguíssemos protegidos. Valdemar pegou o cigarro, tragou e soprou a fumaça em seu peito, braços e pernas. Dele o cigarro seguiu para todos, que repetiram o gesto fazendo a fumaça ocultar nossas "pessoas-sopro", / häwãg/, de nossos possíveis predadores.

Da terra firme nas imediações de /Pëd Dëh Moy Höd/, o terreno foi tornando-se arenoso e elevado. Adentrávamos a /Pap Nih Mun/, "Caaatinga do Sarampo" onde muitos antepassados dos caminhantes haviam morrido dessa "doença dos brancos". No alto dessa colina, nossos companheiros deixaram de perceber o caminho. Enquanto errávamos, Kow perguntou se ]. Maria e eu ouvíamos o 
som dos pássaros. De repente, não ouvimos mais o cantar dos /uy tak/, /popó/e araras, antes tão presentes durante trajeto. "O Dono da Serra Grande, /Sokw'ät ĩh/, não gosta do canto dos pássaros. Por isso, mantêm-nos afastados das imediações de sua morada", comentou Kow em língua Hup.

Em meio ao sol já baixo, exauridos e decepcionados, João Paulo e José comunicaram ao grupo que faríamos acampamento próximo ao /D’ög Dëh/. Preocupados com as onças que caminham à noite na beira do rio em busca de suas presas, prepararam uma tocha com o barro seco de casa de cupim cuja fumaça ocultaria o acampamento do olhar das feras. Após comermos nossa refeição de carne de tatu e mojeca de peixe, deitados na rede, começamos a ouvir o som assombroso de um /B'atib' Sõ/, um "homem-sombra" chamado Sõ. "Conforme ele anda pela mata, seu pássaro acompanha-o pelo ar", contou Valdemar. Ao meu lado, ele bateu a mão forte contra o peito para mostrar a respiração ofegante do Ser. O monstro tem um buraco no peito e faz um barulho terrível conforme anda e respira.

A escuridão, a perda do caminho, o medo das onças e outros seres da mata pareciam criar um espaço onde o terror era mediado pela narrativa (Taussig, 1987). Após a escuta amedrontadora do som desse /b'atib'/, começamos a conversar sobre os perigosos seres que habitam a Serra Grande. João Paulo contou a história de /Hup ãy/, uma mulher que morava no alto de uma árvore e, todos os dias, subia por uma escada para sua morada. Fora surpreendida por uma onça que a devorou impiedosamente. Ao meu lado, J. Maria disse ter ouvido o som de /Döh Ãy/, uma terrível caçadora canibal, e imitou seu grito: UAAA!!! UAAAA!!! Certa vez, caçando macacos /öh/ com seu pai durante a noite, ouviu esse mesmo grito e saiu correndo. Receosos do encontro com tais seres, adormecemos pelo esgotamento total de nossas forças.

A conversa sobre os sonhos inicia-se com o tema /ãyd'äh sõh ni/, "ter sonho com mulheres", cujo sentido será ampliado pela adjetivação das mulheres como /ya'am däh/, "onças", e pela marca de proveniência /-duuy/, "oriundo de". A Serra Grande, lugar de origem dessas mulheres-onça, é também para onde deslocou-se a pessoa-sopro de meu interlocutor para a interação sedutora e perigosa. Ao enunciar um sonho com minha própria esposa, evidencio o sentido do perigo intercurso sexual. A proteção será garantida pelo encantamento protetivo que reforça o entendimento global dos acontecimentos dos sonhos como ruins. Se a conversa de [13.07] aponta para uma indexicalização que aproxima a serra, a cidade e a aldeia pelo jogo com soldados-onça, agora o espaço da serra e o gênero feminino sinalizam o risco da interação e nossa imersão numa /ya'am däh nih s'ah/, "terra de onça", entendida como um campo dominado por seu ponto de vista onde todos nós podíamos apenas assumir a posição de presas e vítimas. Situávamo-nos num espaço da morte, onde muitos antepassados tinham sofrido e falecido com o sarampo. 
As conversas sobre sonhos parecem inserir as percepções num movimento reflexivo do tipo "para frente e para trás" onde a interação verbal e perambulatória reverberava sentidos ancorados em diferentes dimensões socioespaciais povoadas pela intencionalidade de perigosos outros sejam eles Brancos, com suas epidemias, sejam eles sedutoras mulheres-onça, /Döh ãy/ ou /Hup ãy/, habitantes da serra (Taussig, 1987). Pensando com Santos-Granero (1998), a toponímia "caatinga do sarampo" pode ser tomada como um "topograma", um elemento da paisagem imbuído do significado histórico do poder aniquilador da afecção epidémica dos "brancos".

O "silêncio dos pássaros", o "som do sombra" e o "grito da caçadora canibal" colocam-se como sinais diacríticos para a percepção passagens entre a /hib'ah tẽh däh nih s'ah/, "a terra dos ancestrais hupd'äh", uma região de memórias e afetos, uma "terra das onças", dominada pelas intenções predatórias, e uma "terra do sarampo", onde a afecção epidêmica dos "brancos" sinaliza a morte e leva à errância. Imagens oníricas, sons e toponímia compõe um denso plexo semântico a justapor a "imanência dos inimigos" e a história da "invasão branca" numa passagem aos limites-tensão entre mundos (Viveiros de Castro, 2002). Certamente, esses modos de interação subjuntivos que nos afetavam corroboraram para que o caminho não aparecesse e errássemos, indo para frente e para trás, buscando desvios na encruzilhada de um perigoso devir outro (Favret-Saada, 2009).

16 de julho de 2016.

Balançando em sua rede, Kow cantava um kapiwaiá, o /Yëw Yam/, "Canto do Tatu". Ao seu lado, Valdemar contou que em seu sonho vagava pelo topo da Serra Grande. O sonho surgia como/naw sõh nii/, "sonhar bom". Parando o canto, Kow disse ter sonho com coca. No alto da serra, estava a comer coca e conversar com Marino, seu falecido afim. Ao lado, J. Maria sorria ao lembrar seu sonho com festa na aldeia de /Tat Dëh/.

\section{Língua Hup}

Valdemar (V). Säwä'äy

am, Niro!

Danilo (D). Säwä'äy!

V. Naw aman sõh ni?

\section{Tradução}

Valdemar (V). Você está acordando, Danilo!

Danilo (D). Estou acordando!

V. Tem sonho bom para você? 


\section{Língua Hup}

D. Sõh ni nih.

Minig õhõy.

V. Paç Pög sõh ni ãh.

Pöh sakay. Pöh!!!

Paç busöan.

D. Am ta' Kow. Sõh ni am?

Kow. Pũ'ũk sõh ni ãh.

Marino ãh bab idiły.

Paç busöan, Marino

ãh pu'uk wedey.

Bab idity!

Naw sõh ni.

Nik'an, São Gabriel

an tihan meh y't'h.

\section{Tradução}

D. Eu não tenho sonho não.

Dormindo direto.

V. Em meu sonho, a Serra Grande.

Subindo al to. Muito alto!!!

Para o topo da Serra.

D. Você Kow, tem sonho?

K. Eu tenho sonho com coca.

Eu conversando com Marino.

No topo da Serra Grande,

Marino e eu comendo coca.

Conversando.

Sonho bom.

Para lá em São Gabriel

mataram-no.

D. Hipãhãy ãhãh. Hãwäg hi hũ'ũp nup. D. Eu sei. Muito triste isso.

José Maria. Tat Dëh sõh

ni ãhãh.

Huptök ägäy.

Yam yamay.

Naw sõh ni
José Maria. Tenho sonho com Taracuá Igarapé.

Bebendo caxiri.

Cantando e dançando!

Sonho bom! 
Logo após nossa conversa, cada um de meus interlocutores levantou-se para banhar e verificar as malhadeiras e varas deixadas na beira rio. Após a saída do acampamento, ainda demoramos cerca de uma hora até encontrarmos as pistas de nossa viagem de 2012. Agora, seguros quanto ao percurso, nossos companheiros dedicaram-se mais à observação do entorno orientada para a caça e para a coleta. Rastros de animais como pegadas, fezes e pelos foram identificados. Buscavam as árvores de onde pendiam cipós de arumã para que, no retorno, esposas, mães e irmãs tecessem cestos aturá.

Num dado momento, J. Maria aproximou-se e, orgulhoso, disse ter matado um jacaré. Ele, José e Edmar perseguiram o rastro da cauda na areia do igarapé. Mataram-no com um golpe forte de terçado. Logo, Edmar juntara-se ao grupo carregando a vítima nas costas. À medida que nos aproximávamos da Serra Crande, situávamo-nos numa região intensamente habitada por animais como antas, caititus, pacas, cotias, jacarés, veados e onças. Nosso caminho era perpassado a todo momento pelas pegadas dos bichos. Seguindo a percepção apurada dos mais velhos, eram sempre os jovens que animavam os demais a ir atrás de um dos bichos.

Kow chamava a atenção dos rapazes e a nossa para as nuvens escuras e trovões que sinalizavam a presença dos habitantes da Serra Grande: /Paç Pög Cidade Crande, Hupd'äh däb nii, tëg hõ ĩh däh, amih bab'däh, Niro/, "a Serra Crande é uma Cidade Grande, há muita gente, brancos, seus parentes Danilo". Contou que /Sokw’ät ĩh/, o dono da serra, é bravo. Não gosta do barulho das crianças e nem do canto dos pássaros, mas, como na "cidade dos brancos", ele faz festanças com seus poderosos aparelhos de som. Já perto da serra, quando chegamos ao local de acampamento dos antigos, João Paulo apontou para um bolo de pelos no chão. Tratava-se da vítima de uma onça. Como todos sabem, essa clareira boa para acampar é o cenário de uma narrativa mítica. A história conta que um homem hup teve que fugir para não ser devorado por seu cunhado, um homem-sombra, pescador de onças. Do ponto de vista do homem-sombra, as terríveis felinas eram apenas peixes traíra que ele pescava colocando pacas, minhocas para ele, em seu anzol. Diante dos sinais das feras, nessa perigosa paisagem mítica, nosso guia avaliou ser melhor dormirmos em outro ponto do rio (Wright, 2013).

Pensando com Shiratori (2013), em meio às dificuldades que passávamos e à possibilidade de não encontrarmos o caminho, as conversas sobre sonhos permitiam entrever desvios possíveis a partir de uma dinâmica de tempo múltiplo por meio da qual "os desvios tornam compossíveis diferentes incompossíveis, fazendo existir passados não realizados, por exemplo" (2013: 124). Os diálogos sobre sonhos permitiam contrafactuar eventos oníricos e não-oníricos, e não meramente antecipar o "futuro" a partir da "manifestação de uma potência fixa de eventos com antecipação independente do que possa acontecer" (Shiratori, 2013: 123). En- 
quanto nos dias anteriores, a conversa sobre sonhos era sucedida pela enunciação xamânica do encantamento protetivo, a prática não foi necessária após a conversa sobre as práticas do "sonhar bom", já que eles evidenciavam desvios possíveis e contrafactuavam os eventos do caminho àqueles dos sonhos indicando possibilidades de retorno e reconcentração das pessoas-sopro dos viajantes.

À minha negativa quanto a ter sonho, Valdemar enuncia o tema do "sonho com a Serra" e descreve o deslocamento de sua pessoa-sopro pelo verbo de movimento /sak/, "subir", acrescido do sufixo dinâmino/-y/. Questionado por mim, Kow precisa o tema de seu sonho como "sonho com coca" e relata a situação de conversa com seu falecido afim, Marino, /Paç busöan/, "para lá no topo da serra". As ações vão assim ancorando-se de modo indexical no espaço da serra onde a alteridade é estabelecida por um "eu" que sobe e vaga no topo, e por um "eu" que conversa e come coca com um afim morto. Diferente das conversas dos dias anteriores, em que o sujeito do discurso posicionava-se em campos relacionais dominados por onças e brancos, "caminhar na serra" e "comer coca com um morto" são ações próprias a uma perspectiva humana hup, assim como a festa de caxiri na aldeia.

O encadeamento dos enunciados sobre sonhos dá à serra os contornos de uma /hib'ah tẽh däh nih sah/, "terra dos ancestrais", onde a peregrinação pelo topo, a conversa da coca e a festa de caxiri são ações ritualizadas que sinalizam a predominância do ponto de vista hup e a possibilidade de continuar pelo caminho (Humphrey e Laidlaw, 2004). Semelhante à diferenciação Pumé do "sonhar bem" como ver longe pela viagem do pumethó (princípio vital), /naw sõh ni/, "sonhar bom" tematiza o movimento da pessoa-sôpro, o bom retorno, a concentração da pessoa-múltipla e o posicionamento em campos mútuos de interação com antepassados (Orobitg, 1998). Entretanto, os trovões e nuvens negras indicados por Kow indicam a passagem ao limite-tensão da "Cidade Grande da Serra" onde um festeiro que detesta o som das crianças e pássaros, faz ecoar suas músicas pelo poderoso som estéreo (Viveiros de Castro, 2002). Por seu ato de mostrar, Kow revelava aos jovens a transição para um mundo onde o domínio era exercido por um uma pessoa magnificada que manejava potências dos brancos e das onças (trovões) para animar a metrópole dos "meus parentes brancos" estéril de crianças e do cantar das aves (Ingold, 2000; Fausto, 2008).

Tiwit, 17 de julho de 2016.

Valdemar riu de meu sonho. Contei que voava sobre a Serra Crande e via a Cidade das Onças. Segundo ele, esse era um /säw sõh nii/, "um sonho de pajé". Contou de seu sonho com anta, uma direção possível do encontro com os "brancos da serra". Juntando-se a nós, José Maria disse ter sonho com dinheiro e briga. 
Atento à conversa, Kow afirmou que eram ações de "sonhar ruim", /paç sõh nii/. Ele faria o /Paç Pög Pöh Sakay Bi'id/, "Benzimento da subida da Serra Crande" para cercar-nos contra a ação maligna dos habitantes da Serra Grande-Cidade como as Gentes-Árvore, Gentes-Raíz, Onças, Soldados, da caçadora canibal /Döh ãy/. A Serra, uma /Hib'ah Moy/, "Morada da Origem”, era também uma "Cidade dos Brancos" tão grande quanto São Paulo e uma "Terra das Onças". Com a ação xamânica, Kow age de modo a contrafactuar os eventos oníricos reduzindo suas potências (Shiratori, 2013).

\section{Língua Hup}

Danilo (D). Säwä'äy am, Valdemar!

Valdemar (V). Säwä'äy!

D. Paç busöan ãh sõh ni.

Wayrö' hamay ãh.

Tih dö moy, tith põpõh moy, tih pöhöw moy, tih s'a moy ãh këëy.

Tuhup!

V. Säw sõh ni aman.

D. Am ta', sõh ni am?

V. Tah sõh ni ãh.

Tëg hõ ĩh däh këy tëg kar’ah.

Paç an d'uuy däh.

]. Maria. ũh mehey sõh nii ãh,

Niro, hup pesaw ĩh, Marcelo.

\section{Tradução}

D. Você está acordando, Valdemar!

V. Acordando!

D.Tenho sonho para lá no alto da serra.

Eu voando.

Vendo a casa vermelha, a casa verde, a casa amarela, a casa preta.

Muito bonito!

V. Há um sonho de xamã para você.

D. E você, tem sonho?

V. Eu tenho sonho com anta.

Verei brancos mais à frente.

Cente da serra.

J. Maria. Danilo, tenho sonho com briga contra um rapaz, Marcelo.

Saindo sangue dele até 


\section{Língua Hup}

Dinhero ãh su'uy.

Dinhero sõh ni, ũh

meh ni tëg kar'ah.

Mora'ap id.

Pinig wä' tëg kar'ah,

Te' in ni tëg kar'ah.

\section{Tradução}

Eu pegando dinheiro.

Tem sonho com dinheiro,

vai ter briga mais para a frente.

Tem três falas.

Vai ouvir história mais pra frente.

Vai ter esposa mais pra frente.

Na trilha para a escalada, Valdemar comentou:

/Paç Pög Cidade. Fábrica niih. St̀k way yit'ty, pë niih tëg kar'ah. Paç Pög tu fábrica niih. Sik way yï' ih. Pay!/, "a Serra Crande é uma cidade. Tem suas fábricas. Saindo, a fumaça faz aparecer doença mais pra frente. A Serra Grande tem fábrica. A fumaça sai. Muito ruim!

Assim, à medida que nos aproximávamos da serra, lugar sagrado dos Hupd'äh, estávamos cada vez mais perto de uma verdadeira metrópole com suas perigosas fábricas, doenças e habitantes canibais. Como aponta Marques sobre os Hupd'äh: "essas cidades de localização difusa na periferia de /nith s'ah/tornam-se uma espécie de centro alternativo do mundo, os perigos e a potência patogênica a ela associados passam a conviver com outros aspectos [...]" (2015: 168).

Seguíamos rápido e quase em silêncio a maior parte do tempo. Já no pé do morro, João Paulo percebeu que a trilha da subida estava limpa e possuía pegadas frescas. /Guerrilhero sib/, "pegada de guerrilheiro", afirmou. Todos ficamos com medo, pois há décadas os morros são utilizados por milícias armadas colombianas para suas atividades de combate, tráfico de drogas e refúgio. Lá no alto, caminhávamos todos muito próximos uns aos outros, falando o menos possível. Nossos guias, João Paulo e Valdemar apenas indicavam a trilha para chegarmos aos "lagos de banhar" que estavam lá desde o início dos tempos. Entretanto, diferente de nossa incursão de 2012, os lagos estavam secos e não pudemos lavar nossos corpos nem beber a água-pura para sonharmos com os antepassados. Apontando para o horizonte, João Paulo mostrou os morros e 
caminhos pelos quais havíamos passado enfatizando a distância e a dificuldade do percurso.

Depois de conversarmos, comentarmos a vista e explorarmos um pouco o topo da serra, nosso guia convocou-nos para a descida. Com extrema velocidade, apoiávamo-nos nos vãos da rocha e íamos lançando nossos corpos para baixo. Caminhávamos com extrema rapidez. /Ya'am däh täw pub. Paç sakay tuk däh/, "as onças estão muito bravas, não gostam que subam a serra", comentou Kow para os rapazes, sugerindo que apertássemos o passo, pois estávamos sendo perseguidos pelas onças predadoras. Após uma tempestade forte que nos surpreendeu já perto da "Caatinga do Sarampo", nosso mentor parou e voltou seu olhar para o chão. Apontou para as pegadas da onça que caminhava à nossa frente. /Säw/, "é o pajé", afirmou sem temer. Para ele, diferente dos trovões de nossas perseguidoras, os rastros indicavam a presença de seu pai, o pajé Armando, com sua roupa de onça a nos proteger.

$\mathrm{Na}$ conversa sobre os sonhos, evidenciam-se alguns recursos discursivos marcantes a essa forma de interação verbal. A expressão/niih tëg kar'ah/, "terá mais à frente", aponta a percepção semântica do tempo múltiplo como relações entre "caminhos à frente" e "caminhos atrás" que permitem desvios possíveis e reposicionamentos para contrafactuar acontecimentos oníricos (Shiratori, 2013). Essa expressão torna-se, a meu ver, um importante recurso de indicialidade constituindo a posição do enunciador num aqui da situação comunicativa, mas também agindo sobre as situações e enunciações implicadas numa sequência de ações possíveis ao longo do caminho visto como um emaranhado de linhas que permitem seguir, recuar, desviar e prosseguir.

Essa parece ser a relação entre os sonhos que suscitam, logo após os diálogos oníricos, enunciações xamânicas protetivas como os benzimentos realizados por Kow para proteger-nos das afecções de não-humanos (onças), coisas (dinheiro) e humanos-outros (brancos), e também das interações com seres habitantes da Serra. Como ]. Maria em [14.07], meu "voo xamânico" era um "sonho ruim", pois nele um "branco" agia como um pajé sem a fabricação do corpo necessária para a metamorfose (Viveiros de Castro, 1979). Em [17.07], o jovem ]. Maria agia violentamente agredindo um rapaz hup, Marcelo, após "pegar em dinheiro" evidenciava o perigo tanto do contato com uma "coisa dos brancos", quanto de, despreparado, agir oniricamente como um xamã. Num maior equilíbrio entre os pontos de vista com os quais se relacionava, Valdemar dizia "sonhar com anta", índice dos "brancos da serra", que situa esses outros na posição da presa.

As conversas sobre as pegadas do guerrilheiro percebidas na trilha e sobre a Serra como uma cidade com fábricas e fumaças patogênicas estendem o sentido da conversa sobre os sonhos para uma indexicalidade que vai evidenciando o modo como, a cada passo, situávamo-nos num espaço de perigosos outros, 
uma Cidade das Onças de localização difusa e que era um centro alternativo pleno em suas potências e perigos metropolitanos (Marques, 2015). O pedido de silêncio diante da "coca das onças" e nossa fuga das predadoras felinas apontam para a simultânea habitação da serra por onças e brancos que não gostam da peregrinação dos Hupd'äh. Ao mesmo tempo, a incursão à serra fortalecia as capacidades xamânicas dos viajantes e principalmente dos benzedores. Como os "soldados-onça" em [13.07], as imagens tensas da "fumaça patogênica", das "pegadas do guerrilheiro" e da "perseguição das onças" suscitaram sentimentos de medo que aceleraram o ritmo da caminhada de volta. Apenas a percepção das pegadas do "pajé-onça", aquele que age em meio a um "infinito de perspectivas em conflito" na busca por atenuar ou intensificar tensões e pontos de vista, foi capaz de assegurar mais uma vez nossos passos no retorno (Taussig, 1987).

\section{SONHOS A CAMINHO DA CIDADE DAS ONÇAS}

Refletindo sobre relatos de xamãs de viagens oníricas hup, Marques aponta para a localização difusa das cidades, já que a "'prefiguração dos brancos' parece dar-se por um processo de reversão da figura-fundo da cidade [...] que surge como a imagem geral do fundo cósmico desde o qual os Hupd'äh vivos se destacam [...]" (2015: 236). Procurarei agora evidenciar alguns aspectos discursivos presentes nos diálogos que permitem a composição discursiva desse sociocosmos de multiplicação de perspectivas ambulantes possibilitando aos viajantes a subversão tática das intenções predatórias de brancos e onças ao longo do caminho (Viveiros de Castro, 1996; Cow, 2001; De Certeau, 2011).

A pergunta sobre o sonho em alguns diálogos:/Sõh ni am?/ convida à fala de um dos interlocutores e estabelece o tema da conversa. As posições de nossas redes ou o manuseio de gravetos, panelas e espetos com peixes garantiam uma formação interativa através da qual todos podíamos nos entreolhar e conversar enquanto estávamos /säwäy/, "acordando", na transição entre o sono e a vigília, entre a dispersão e concentração da pessoa múltipla (Lolli, 2010). Entendo esse arranjo como um agrupamento ágil para a ação xamânica protetiva, caso os diálogos evidenciassem acontecimentos oníricos ruins. Desprovidos da capacidade diplomática plena do xamã de transitar por uma profusão de coletividades e perspectivas, os viajantes partilham seus "sonhos" e avaliam taticamente a necessidade de encantamentos protetivos, da alteração da rota, de desvios ou da impossibilidade de continuidade, buscando não dominar ou vencer, mas se esgueirar e ocultar-se (Cesarino, 2008; De Certeau, 2011).

A primeira pessoa do singular, /ãh/, "eu", é utilizada para constituir o sujeito como uma imagem de si no discurso que, oniricamente, situa-se em espaços em continuidade com o contexto de enunciação (Langdon, 2004). O "Eu" do 
discurso coincide com aquele do enunciador sendo também a própria pessoa-sopro a estender sua presença e ações da situação de interlocução no caminho até a cidade, o topo da serra, a aldeia, numa indexicalidade expansiva (Urban, 1989). Ao "jogar futebol com soldado-onça" [13.07], "estar com as mulheres onça na serra" [15.07], "subir e vagar sozinho no topo da serra" [16.07] e ao "ver anta" [17.07], Valdemar situa o eu discursivo em diferentes pontos do sociocosmos da cidade-serra, delineia dialogicamente sua identidade na interação com onças e brancos que se apresentam sob aparências amistosas (soldado), sedutoras (mulher), mascarando a intenção predatória. A ironia é a figura de linguagem que marca a enunciação de J. Maria: "eu sou xamã", e serve como um metadiscurso sobre sua enunciação em que matava um homem hup [14.07] ou batia num rapaz [17.07] desdobrando em si a perigosa alteridade de um devir xamã (Urban, 2000). "Comer coca com Marino", "vagar pela serra" e "beber caxiri com parentes" [16.07] mostram o "eu" de Kow numa alteriadade próxima ao parente morto, aos ancestrais e aos parentes.

Todos os relatos de sonhos envolvem deslocamentos do Ser pelo mundo mas, tais movimentos são suprimidos ou aludidos de modo breve por verbos de movimento como/säkäy/, "subindo" [16/07], ou pelo uso do sufixo nominal direcional /an/, "para lá", como em /paç busöan/, "para o al to da serra" [15/07], / São Gabriel an/, "para lá em São Gabriel" [13/07]. Discursivamente, entendo que o sentido de movimento do "deslocamento onírico" vai sendo expresso pelo emprego de verbos de movimento compostos a partir do uso do sufixo verbal dinâmico /-y/ e do uso sufixo nominal direcional /an/-caso oblíquo direcional (Ramirez, 2006; Epps, 2008).

De modo interessante, para precisar quem era seu interlocutor no evento onírico [16.07], Kow conta que ele fora morto /nik'an/, "para lá", em São Gabriel, marcando intensamente a distância do evento tanto espacialmente - longe na cidade-, como temporalmente numa ação passada concluída-morte do interlocutor-com o sufixo declarativo /-h/ (Epps, 2008). É possível perceber que um traço comum aos enunciados vem a ser o uso do sufixo verbal dinâmico (-Vy) para descrever as ações oníricas em: [13.07]; [16.07]; [17.07]. O uso da forma - Vy com a função dinâmica estabelece a situação como um processo dinâmico indicando a continuidade temporal (Epps, 2008, p. 524). Segundo Epps, "The Dynamic marker has an aspectual function, and is usually preferred when describing events that are on-going and dynamic in relation to the speech moment (or a more general frame of temporal reference; cf. §12.2)" (2008: 921). Nos enunciados acima, os interlocutores empregam a função dinâmica no uso dos verbos: /saka-y/, "subindo", "bab'tdi-y", /yama-y/, "cantando", /ägä-y/, "bebendo", enfatizando a continuidade das ações que realizavam no al to da Serra Grande, na Cidade de São Gabriel e na aldeia de Tat Dëh. As ações parecem não se inter- 
romper e constituir o sentido de uma temporalidade simultânea e paralela ao evento narrativo (Bauman, 1977). Sua conclusão e a concentração da pessoa-sopro realizam-se pela execução dos benzimentos protetivos que reúnem, cercam e ocultam os viajantes.

Pensando com Ingold, os sons de animais, não humanos e antepassados estabelecem sentidos aos contextos nos quais são ouvidos (2000: 104). Sons e barulhos são percebidos como vozes que revelam os pontos de vista intersubjetivos presentes nessa paisagem polifônica (Graham, 1984) e "o dialogismo acena concomitantemente para um atravessamento de outros discursos, constitutivo da própria língua, realizável por um jogo fronteiriço [...] num atravessamento do sujeito pela alteridade da interlocução" (Flores e Teixeira, 2005: 45). A percepção do entorno ao longo de nosso percurso de observação em sonho e na caminhada foi evidenciando algumas passagens, limites-tensão em que as potências da predação e da cidade eram sinalizadas pelo silêncio dos pássaros, pelas sedutoras canibais (Onças, hup-ãy e Döh-ãy), e pelos gritos do homem-sombra (Ingold, 2000; Viveiros de Castro, 2002).

Nesse sentido, as sequências diárias de conversas sobre sonhos e as situações vividas ao longo do caminho vão revelando como esse grupo de viajantes hup, dotado diferencialmente com habilidades xamânicas, experiencia as passagens aos limites-tensão entre as múltiplas "terras", /s'ah/, planos-cósmicos fundidos na simultaneidade concêntrica de múltiplos espaço-tempos. Abertas pelo caminho, essas passagens aos limites-tensão configuram campos perceptivos onde eventos oníricos, sons e presenças de outrem situam uma memória ritual a complexificar imagens quiméricas de "brancos", "onças" e "soldados". A deixis discursiva vai constituindo-se através de posicionamentos dos enunciadores nas "terras", campos perceptivos nomeados como: Cidade, aldeia e Serra Crande, e que são expressões de mundos possíveis para que os viajantes internalizem relações exteriores e externalizem suas capacidades xamânicas (Viveiros de Castro, 2002).

Desse modo, os diálogos oníricos constituem-se como uma forma constante de interações verbais entre os viajantes que permite refletirem mutuamente sobre suas observações sensíveis das situações vivenciadas em sonho, das percepções ao longo dos caminhos e das incursões à cidade para posicionamentos táticos face à progressiva interação com perspectivas outras e a penetração na Cidade das Onças (Houseman e Severi, 2009). Os deslocamentos por percursos de observação vão proporcionando uma sucessão de vistas, de vozes, de intencionalidades predatórias, de afetos e afecções na justaposição de paisagens oníricas, míticas e entornos florestais. Situada em plena Serra Grande, a Cidade das Onças parece ser um nexo espacial, um sociocosmos de multiplicação de perspectivas a desdobrar alteridades poderosas e ameaçadoras para além dos domínios urbanos e florestais circunscritos (Viveiros de Castro, 2002). 


\section{CONSIDERAÇÕES FINAIS}

A mobilidade onírica parece ser um fenômeno importante para os mais diversos povos, seja ela compreendida num modo metafórico como o deslocamento de um self-onírico ou da pessoa múltipla, seja tomada como o deslocamento real da pessoa ou da mente pelo cosmos (Tedlock, 1987). Os momentos de enunciação dessas experiências constituem formas constantes de interação verbal que permitem contrafactuar os eventos cotidianos e os acontecimentos oníricos (Shiratori, 2013).

Como para os Mehinaku (Gregor, 1981) e Ojibwa (Hallowell, 1966), a ênfase das conversas dos Hupd'äh está em refletir mutuamente e de modo breve sobre os deslocamentos reais do sopro vital (pessoa-sopro) durante o sono, o que permite avaliar as perspectivas imanentes aos mundos atravessados pelos deslocamentos, os riscos da predação e a necessidade ocasional de agir xamanicamente para proteger os viajantes de ameaças quando a "terra dos Hupd'äh e de seus antepassados" passa a ser uma "terra das onças" que é simultaneamente uma "cidade dos brancos".

As conversas sobre os sonhos situam, assim, contextos concretos para que os jovens caminhantes aprendam com seus mentores a partir de seus movimentos como pessoas-sopro e como pessoas-corporificadas. A interlocução permite posicionarem-se, por seus movimentos e enunciados, numa vasta região cosmopolítica para a negociação da passagem com o entorno (Ingold, 2000). Deslocando-se entre planos-cósmicos ao rés do chão, os viajantes procuram sempre subverter as intenções predatórias de ameaçadores Outros na tentativa de transitar por espaços povoados por suas lembranças de antepassados, costumes, vivências da infância e potências urbanas.

Partindo de uma ação de proteção territorial (PGTA) e apoio para a atenuação dos problemas suscitados pelas cada vez mais constantes incursões à cidade de São Gabriel, esse trabalho procurou mostrar como, ao logo do caminho, uma profunda reflexão sobre as mudanças no mundo vivido dos Hupd'äh é realizada através dos diálogos sobre sonhos e das estratégias para lidar com uma predação que expande suas fronteiras na simultaneidade espaço-temporal da Serra-Crande/Cidade. Espero ter apontado a potência dessas formas agenciais-semióticas que parecem ajudar os caminhantes a firmarem seus passos e seguir em frente em meio aos devires predatorórios e aos mundos possíveis.

Danilo Paiva Ramos é Professor adjunto do Dep. Antropologia e Etnologia da Universidade Federal da Bahia (UFBA). Possui pós-doutorado em Antropologia 
Linguística pela Universidade do Texas (2015-2016, BEPE-Fapesp) e em Antropologia Social pela USP (2014-2017, Fapesp). É assessor do povo Hupd'äh para a construção de seus Planos de Gestão Territorial e Ambiental (PGTA-Hup).

\section{REFERÊNCIAS BIBLIOCRÁFICAS}

ALBERT, B.

2000 "O ouro canibal e a queda do céu". In ALBERT, B e RAMOS,

A. (orgs.). Pacificando o branco. São Paulo, Ed. Unesp.

AMORIM, Marilia

2005 "Cronotopo e exotopia". In BRAIT, Beth (org.). Bakhtin:

outros conceitos chave. São Paulo, Contexto.

ANDRELLO, Geraldo

2006 A cidade do índio: transformações e cotidiano em lauareté. São Paulo, Ed. Unesp.

ATHIAS, Renato

1995 Hupdah-Maku/Tukano: Les Rélations inègales entre deux societés du Uaupés Amazonien (Brésil). Paris, tese de doutorado, Université Paris X-Nanterre.

1998 "Doença e cura". Horizontes Antropológicos, Porto Alegre, vol. 4, n. 9: 237-261.

2006 “Os Hupd'äh". In RAMIREZ, Henri (org.). A língua dos Hupd'äh do Alto Rio Negro. São Paulo, Saúde Sem Limites.

BAKHTIN, Mikhail

1981 Marxismo e filosofia da linguagem. São Paulo, Hucitec.

2006 Estética da criação verbal. São Paulo, Martins Fontes.

BARCELOS NETO, Aristóteles

2008 Apapaatai. São Paulo, Edusp.

BATESON, Gregory

1958 Naven: A Survey of the Problems Suggested by a Composite Picture of the Culture of a New Guinea Tribe Drawn from Three Points of View. Stanford, Stanford University Press. 
BAUMAN, R.

1977 Verbal Art as Performance. Illinois, Waveland press.

BENJAMIN, Walter

1935 "Materials for the Exposé of 1935". The Arcades Project. pp. 899-918.

BUCHILLET, Dominique

1983 Maladie et mémoire des origins chez les Desana du Uaupés.

Paris, tese de doutorado, Université de Paris X.

CESARINO, Pedro N.

2008 "Babel da floresta, cidade dos brancos: os Marubo no trânsito entre dois mundos". Novos Estudos, vol. 82: 133-148.

DE CERTEAU, Michel

2011 A invenção do cotidiano. Vol. 1. Petrópolis, Vozes.

ECCAN, Dorothy

1952 "The Manifest Contento of Dreams: A Challenge to Social Science". American Anthropologist, vol. 54: 469-485.

EPPS, Patience

2008 A Grammar of Hup. Virginia, tese de doutorado, University of Virginia.

FAUSTO, Carlos

2008 "Donos demais: maestria e domínio na

Amazônia". Mana, vol. 14, n. 2: 329-366.

FAVRET-SAADA, Jeanne

2009 Désorceler. Paris, Éditions de l'Olivier.

FIRTH, Raymmond

1934 "The Meaning of Dreams in Tikopia". In EVANS-PRITCHARD,

E.E.; FIRTH, R.; MALINOWSKI, B.; e SCHAPERA, I. (orgs).

Essays Presented to C. G. Seligman. Londres, Kegan Paul.

FLORES, V. e TEIXEIRA, $M$.

2005 Introdução à linguística da enunciação. São Paulo, Contexto. 
FUNDAÇÃO NACIONAL DO ÍNDIO. COORDENAÇÃO

GERAL DE GESTÃO AMBIENTAL (org.)

2013 Plano de gestão territorial e ambiental de terras indígenas:

orientações para elaboração. Brasília, FUNAI.

GOW, Peter

1993 "Cringos and Wild Indians. Images of History in Western Amazonian

Cultures. La Remontée de l'Amazone". L'Homme, v.126-8, n. esp.: 327-347.

2001 An Amazonian Myth and Its History. Oxford e

Nova York, Oxford University Press.

GRAHAM, Laura

1984 Performing Dreams. Austin, University of Texas Press.

GRECOR, Thomas

1981 "Far, Far Away My Shadow Wandered...: Dream Symbolism and Dream Theories of the Mehinaku Indians of Brazil".

American Ethnologist, vol.8, n.4: 709-720.

GUMPERZ, John ].

1982 Discourse Strategies. Cambridge, Cambridge University Press.

HALLOWELL, A. I.

1966 "The Role of Dreams in Ojibwa Culture". In. VON

GRUNEBAUM, E. e CAILLOIS, Roger (orgs.). The Dream and

Human Societies. Berkeley, University of California Press.

HOUSEMAN, Michael e SEVERI, Carlo

2009 Naven ou le donner à voir. Paris, CNRS-Éditions.

HUMPHREY, C. e LAIDLAW, ].

2004 The Archetypal Actions of Ritual. Oxford, Clarendon press.

INCOLD, Tim

2000 The Perception of the Environment. Londres, Routledge.

KELLY, José

2016 On Yanomami Ceremonial Dialogues: A Political

Aesthetic of Metaphorical Agency. (no prelo). 


\section{LANGDON, E. ].}

2004 "Shamanismo y sueños: Subjetividad y representaciones de sí mismo en narrativas de sueños siona". In CIPOLLETTI, Maria Susana (org.). Los mundos de abajo y los mundos de arriba: Individuos y sociedad en las Tierras Bajasy los Andes. Quito, Edit. Abya Yala.

2013 "A viagem à Casa das Onças?: Narrativas sobre experiências extraordinárias". Revista de Antropologia, vol. 56, n. 2: 183-212.

LIMA, Tânia Stolze

2005 Um peixe olhou para mim. São Paulo, Editora Unesp.

LINCOLN, Jackson S.

1935 The Dream in Primitive Cultures. Baltimore, Williams e Wilkins.

LOHMANN, Roger I.

2003 Dream Travelers: Sleep Experiences and Culture in the Western Pacific. Nova York, Palgrave Macmillan.

LOLLI, Pedro

2010 As redes de trocas rituais dos Yuhupdeh no igarapé Castanha, através dos benzimentos (mihdïd) e das flautas jurupari (Ti'). São Paulo, tese de doutorado, Universidade de São Paulo.

MALINOWSKI, Bronislaw

[1927] 1949 Sex and Repression in Savage Society.

Nova York, The Humanities Press.

MARQUES, Bruno

2015 Os Hupd'äh e seus mundos possíveis: transformações espaço-temporais do Alto Rio Negro. Rio de Janeiro, tese de doutorado, Museu Nacional.

OROBITC CANAL, Gemma

1998 Les Pumé et leurs Rêves. Amsterdam, Éditions des archives comtemporaines.

O'NEIL, Carl

1965 "A Cross-Cultural Study of Hunger and Thirst Motivation Manifested in Dreams". Human Development, vol. 8: 181-193. 
RAMIREZ, Henri

2006 A língua dos Hupd'äh do Alto Rio Negro. São Paulo, Saúde Sem Limites.

RAMOS, Danilo

2013 Círculos de coca e fumaça: encontros noturnos e caminhos vividos pelos Hupd'äh (Maku). São Paulo, tese de doutorado, Universidade de São Paulo.

\section{REICHEL-DOLMATOFF, Gerardo}

1986 Desana: Simbolismo de los Indios Tukano del Vaupés. Bogotá, Procultura.

REID, Howard

1978 "Dreams and Their Interpretation among the Hupd'äh Maku Indians of Brazil". Cambridge Anthropology, vol. 4, n. 3: 2-29.

1979 Some Aspects of Movement, Growth and Change Among the Hupdu Maku Indians of Brazil. Cambridge, tese de doutorado, University of Cambridge.

SANTOS-GRANERO, Fernando

1998 "Writing History into the Landscape: Space, Myth, and Ritual in Contemporary Amazonia". American Ethnologist, vol. 25, n. 2:128-148.

SEARS, Walter

1948 The Navaho and Yir-Yront: Their Primitive Dreams.

Cambridge, tese de doutorado, Harvard University.

SEVERI, Carlo

2002 "Memory, Reflexivity and Belief: Reflections on The Ritual Use of Language". Social Anthropology, Cambridge, 10 (1): 23-40.

2004 "Capturing Imagination: A Cognitive Approach to Cultural Complexity". Journal of the Royal Anthropological Institute, Londres, 10 (4): 815-838.

SHIRATORI, Karen

2013 O acontecimento onírico ameríndio: o tempo desarticulado e as veredas do possível. Rio de Janeiro, dissertação de mestrado, Museu Nacional.

SILVERSTEIN, $M$.

1992 "The Indeterminacy of Contextualization: When is Enough Enough?". In. AUER, P. e DILUZIO, A. (orgs.). The Contextualization of Language. Amsterdam, John Benjamins. 
TAUSSIG, $M$.

1987 Shamanism, Colonialism and the Wild Man. Chicago,

The University of Chicago Press.

TEDDLOCK, Barbara

1987 "Dreaming and Dream Research". In TEDDLOCK, Barbara (org).

Dreaming: Anthropological and Psychological Interpretations. Nova

York, School of American Research Advanced Seminar Series.

TYLOR, Edward B.

(1877) [1871] Primitive Cultures. 2 vols. Nova York, Henry Holt and Company.

URBAN, Greg

1989 “The 'l' of Discourse". In LEE, B. e URBAN, G. (orgs). Semiotics, Self, and Society. Berlin, Mouton de Gruyter.

1991 A Discourse-Centered Approach to Culture. Austin, Hats Off Books.

VIVEIROS DE CASTRO, Eduardo

1979 "A fabricação do corpo na sociedade xinguana".

Boletim do Museu Nacional, n. 32: 40-49.

1996 "Images of Nature and Society in Amazonian Ethnology".

Annual Review of Anthropology, vol. 25: 179-200.

2011 A inconstância da alma selvagem. São Paulo, Cosac Naify.

WATSON, R. e GASTALDO, E.

2015 Etnometodologia e análise da conversa. Rio de Janeiro, Dd. Vozes.

WILLIAMS, F.

1936 “Papuan Dream Interpretations”. Mankind, vol. 2, n. 2: 29-39.

WRIGHT, R.

2013 Mysteries of the Jaguar Shamans. Londres, University of Nebraska Press. 


\section{ABSTRACT}

In this work I seek to understand the relation between conversations about dreams and traveling events which took place during a trip to /Paç Pög/, the "Big Mountain". The relation between dreams and cosmic displacements have been well exploited in studies on amerindian and mealnesian peoples. It is important to highlight how these oniric itineraries allow experiences in several cosmic levels as well as in big cities where meetings, dialogues and interactions with sodiers, missionaries, merchants reveal images of tension or montages (Taussig, 1987). Based on Bakhtin's dialogical theory of enunciation (1981) and Urban's discourse centered approach (2000), I intend to show how verbal interactions with dreams reveal an intersubjective process of meaning institution by means of a particular mode of indexicalization. In what major, the oniric and dialogical emergence of the Jaguar City as an ontological juxtaposition delineates a critical perception of the fast processes of changes, expropriation and violence caused by the increasingly displacements to the city center of São Gabriel da Cachoeira (AM)?

Recebido em 19 de janeiro de 2017. Aceito em 19 de outubro de 2017.

\section{KEYWORDS}

Dreams, Discourse, Mobility, Hupd'äh, Rio Negro Region 